\title{
Letter: Neurosurgery at war with the COVID-19 pandemic: patient's management from an African neurosurgical center
}

\author{
Fayçal Lakhdar $^{1,2} \cdot$ Mohammed Benzagmout ${ }^{1,2}$
}

Received: 28 April 2020 / Accepted: 10 May 2020 / Published online: 30 May 2020

(C) Springer-Verlag GmbH Austria, part of Springer Nature 2020

\section{Dear Editor,}

We read with interest the Lombardy's experience published by Zoia et al. [8], describing the taken procedures in neurosurgery department and their main recommendations.

Coronavirus disease (COVID-19) is an extremely infectious and life-threatening viral illness that gave rise to the current pandemic; an overwhelming healthcare crisis putting the healthcare system under huge strain. COVID-19 outbreak has also brought along disastrous socio-economic effects and heavily impacted healthcare activities including our neurosurgical field [1-4].

The whole world is facing this challenge which necessitates the engagement of all physicians, including neurosurgeons, to deal with COVID-19 outcomes [5, 6]. In Morocco, the first case of COVID-19 was reported on March 2, 2020; since then, the virus has spread exponentially. Despite the lack of resources and the incapacity of our healthcare system to contain the influx of patients, we managed to implement certain strategies enabling us to optimize healthcare provided to our neurosurgical patients and to minimize the risks health care providers are exposed to. The goals were to educate patients and caregivers about COVID-19 and to ensure safety of the neurosurgery staff. For such and based on our experience, we suggest certain measures concerning surgical scheduling, neurosurgical activity, and residents' education to be adopted as institutional policy which may vary between institutions and regions.

In order to limit the spread of the virus, hospitals restricted access to entrance, reduced visitors' numbers, and limited all unnecessary human interactions. Social distancing for all

Fayçal Lakhdar

lakhdar.faycal@gmail.com

1 Department of neurosurgery, University Hassan II Hospital, Fez, Morocco

2 Clinical Neurosciences Laboratory Faculty of Medicine, University Sidi Mohammed BenAbdellah, Fes, Morocco group-based activities was required and videoconferencing platforms were used for clinical and administrative meetings [7]. Besides, a local monitoring committee was formed and has been in direct daily contact with the central committee responsible for the national management of COVID-19 pandemic at the Ministry of Health.

Seeing the rapid worsening of the situation, hospitals' health care administrators had to profoundly reorganize the whole hospital and convert many wards, including the neurosurgery to COVID-19 care units. Special circuits were created for COVID-19 patients and many medical specialties and staff were transformed into COVID teams after a rapid training.

Hospitalized patients with stable condition waiting for scheduled surgeries were gradually discharged and all hospitalizations for elective surgical procedures were suspended. Consequently, $50 \%$ of the neurosurgical staff had been assigned to the COVID-19 units by March 20, 2020. Altogether, the number of neurosurgical departments in the whole country was reduced and their activity was restricted to emergencies and critically ill patients.

Academic neurosurgery departments have to manage, in addition to urgent and emergent neurosurgical cases, public health concerns regarding disease transmission, and the safety of department staff. For emergent and urgent cases, a COVID-19 swab was routinely carried out, and surgical operations were performed under strict precautions to minimize exposure to the virus. The neurosurgical COVID team (a professor and 2 residents) reviews patient's history, shares radiological findings via mails or telecommunication, and mostly makes decisions for urgent surgical cases. In the operation room, all staff members were required to protect themselves with double surgical gloves and gowns, to decrease the speed of drilling (when needed) to reduce skull bone aerosols, to use dissolvable sutures to minimize patient's return to hospital, and to shorten the operation duration. Endonasal skull base procedures were postponed whenever possible given the high viral load in the nose and nasopharynx. Furthermore, all postoperative 
patients were discharged earlier by the first postoperative day, and quarantined in hotels for at least 2 weeks. We have also deferred or virtualized all unnecessary outpatient visits.

In this period, we have noticed a drastic reduction in the neurosurgical emergencies compared with what we usually have. Routinely, we have an average of three patients to operate in emergency every day. However, only six urgent operations (two chronic subdural hematomas, two decompressive craniotomies, one ventriculoperitoneal shunt, and one posttraumatic spinal fracture) were performed during the last 5 weeks (23 March to 26 April 2020). This decreased activity could be explained by the public "lockdown" and the reduction of road traffic accidents inducing cranial/spinal trauma. However, the fear of contamination might explain the decrease of other emergencies, particularly tumors and vascular diseases. We believe that the current COVID-19 health crisis will have collateral damages related to the delay of consultation, the inability to early diagnose some malignant diseases, and the possible outbreak after return of people to normal activity.

This war against COVID-19 has allowed us to identify many gaps and malfunctioning structures in our health care system, and oriented our thinking towards new ways of directing human resources and a new model of health development where technology, efficiency, and safety prevail. Nevertheless, some questions remain suspended. How can the neurosurgical community be better prepared for a possible second pandemic? How to smoothly integrate neurosurgeon's work into other specialties work? And if the new generation of communication technology proves their safety and efficiency, why not make it part of routine work?

To conclude, all neurosurgical patients presenting respiratory signs and/or neurological manifestations suspicious of COVID-19 should be screened for coronavirus. Besides, additional precautions should be taken henceforth in endoscopic endonasal surgeries.

\section{Compliance with ethical standards}

Conflict of interest The authors declare that they have no conflict of interest.

\section{References}

1. Burke JF, Chan AK, Mummaneni V, Chou D, Lobo E, Berger MS, Theodosopoulos PV, Mummaneni PV (2020) Letter: The coronavirus disease 2019 global pandemic: a neurosurgical treatment algorithm. Neurosurgery. (Apr 3)

2. Cenzato M, DiMeco F, Fontanella M, Locatelli D, Servadei F (2020). Editorial. Neurosurgery in the storm of COVID-19: suggestions from the Lombardy region, Italy (ex malobonum). J Neurosurg. Apr 10:1-2.

3. Dobran M, Paracino R, Iacoangeli M (2020) Letter to the editor by Dobran Mauro, Paracino Riccardo, and Iacoangeli Maurizio regarding Neurosurgery during the COVID-19 pandemic: update from Lombardy, northern Italy. In: Zoia C, Bongetta D, Veiceschi P, Cenzato M, Di Meco F, Locatelli D, Boeris D, Fontanella MM (eds) Acta Neurochir (Wien) Apr 17

4. Jean WC, Ironside NT, Sack KD, Felbaum DR, Syed HR (2020) The impact of COVID-19 on neurosurgeons and the strategy for triaging non-emergent operations: a global neurosurgery study. Acta Neurochir (Wien). (Apr 21)

5. Kondziolka D, Couldwell WT, Rutka JT (2020). Introduction. On pandemics: the impact of COVID-19 on the practice of neurosurgery. J Neurosurg. Apr 10:1-2.

6. Pesce A, Palmieri M, Armocida D, Frati A, Santoro A (2020) Letter: Neurosurgery and coronavirus (COVID-19) epidemic: doing our part. Neurosurgery Apr 15. pii: nyaa115

7. Sun Y, Mao Y (2020) Editorial. Response to COVID-19 in Chinese neurosurgery and beyond. J Neurosurg.Apr 10:1-2

8. Zoia C, Bongetta D, Veiceschi P, Cenzato M, Di Meco F, Locatelli D, Boeris D, Fontanella MM (2020) Neurosurgery during the COVID-19 pandemic: update from Lombardy, northern Italy. Acta Neurochir (Wien) (Mar 28)

Publisher's note Springer Nature remains neutral with regard to jurisdictional claims in published maps and institutional affiliations. 